\title{
Aechmea rodriguesiana (L. B. Sm.) L. B.Sm. (Bromeliaceae) uma espécie endêmica da Amazônia brasileira
}

\author{
Gardene Maria de SOUSA", Maria das Graças Lapa WANDERLEY² \\ RESUMO \\ Aechmea subgênero Chevaliera (Gaudich. ex Beer) Baker está representado na Amazônia brasileira pelas espécies A. fernandae \\ (E. Morren) Baker e A. rodriguesiana (L. B. Sm.) L. B. Sm., sendo a última restrita para esta região. A. rodriguesiana se caracteriza \\ pelas flores dispostas em racemo de espigas, com brácteas florais ovais, margens inteiras, envolvendo o ovário e pelas pétalas \\ alvas e cuculadas. O presente trabalho apresenta a complementação da descrição e ilustraçôes desta espécie. São apresentados \\ dados de distribuição geográfica, hábitats e fenológicos.
}

PALAVRAS-CHAVE

Aechmea, Chevaliera, Bromeliaceae, Amazônia brasileira.

\section{Aechmea rodriguesiana (L. B. Sm.) L. B.Sm. (Bromeliaceae), an endemic species of the Brazilian Amazon}

\section{ABSTRACT}

Aechmea subgenus Chevaliera (Gaudich. ex Beer) Baker, is represented in the Brazilian Amazon by two species: A. fernandae (E. Morren) Baker and A. rodriguesiana (L. B. Sm.) L. B. Sm., the latter being restricted to this region. A. rodriguesiana is characterized by flowers arranged on racemes of spikes, oval floral bracts with entire margins that completely surround the ovary, and by cuculate white petals. The present work has as main goal to complement the description and illustration of this species, exclusive to the Brazilian Amazon, allowing its recognition and conservation. Data on geographical distribution, habitat, and phenology are presented.

\section{KEYWORDS}

Aechmea, Chevaliera, Bromeliaceae, Brazilian Amazon. 


\section{INTRODUÇÃO}

Bromeliaceae, com distribuição essencialmente neotropical, é constituída por cerca de 56 gêneros e 3.010 espécies (Luther \& Sief 1994, 1997; Luther 2000, 2001, 2004). No Brasil, os representantes da família encontram-se distribuídos em praticamente todos os ecossistemas, desde o nível do mar até as regiōes montanhosas de altitudes mais elevadas, atingindo ca. $4.000 \mathrm{~m}$ (Smith \& Downs 1974, 1977, 1979).

$\mathrm{Na}$ Amazônia brasileira os representantes de Bromeliaceae são encontrados com maior freqüência em locais de vegetação de baixios, campina, campinarana e igapó. Apesar da menor diversidade genérica e específica da família em relação às regiōes florestais do leste do Brasil, a Floresta Atlântica, e as de formaçôes abertas da Cadeia do Espinhaço, algumas espécies da região amazônica, são pouco conhecidas e, em geral, mal representadas nas coleçōes de herbários. É freqüente exsicatas de herbários incompletas e indeterminadas, em parte devido à dificuldade de coleta dos exemplares de grande porte e, cujas folhas são fortemente espinescentes, característica comum nos representantes da família.

Destaca-se para os estudos das Bromeliaceae da amazônia brasileira o levantamento da flora da Reserva Ducke, realizado por Ribeiro et al. (1999), onde foram registrados sete gêneros e 13 espécies com representantes das três subfamílias.

Aechmea Ruiz \& Pavon, o maior gênero da subfamília Bromelioideae, possui cerca de 220 espécies, distribuídas por toda a América Tropical (Smith \& Downs 1979; Luther 2000, 2001, 2004).

Atualmente, são aceitos oito subgêneros para Aechmea, reconhecidos essencialmente pelo padrão de inflorescência e caracteres florais, especialmente em relação à morfologia da sépala e dos apêndices petalíneos (Smith \& Downs, 1979).

O subgênero Chevaliera é constituído por 21 espécies, distribuídas desde o sul do México até o Peru e Brasil. A maior ocorrência brasileira é na costa leste, onde habita predominantemente formaçóes florestais úmidas e sombreadas. Pode ocorrer também em áreas mais abertas, como em vegetação de restinga (Sousa, 2004). Na Amazônia brasileira são referidas duas espécies do subgênero Chevaliera: Aechmea fernandae e $A$. rodriguesiana, sendo essa última, restrita para a região (Sousa, 2004).

O objetivo do presente trabalho é fornecer uma descrição mais completa para Aechmea rodriguesiana, uma vez que na obra original a diagnose é incompleta, sendo baseada apenas em um único material em fruto, além da ausência de informaçôes sobre sua distribuição geográfica.

Durante a realização da revisão taxonômica de Aechmea subg. Chevaliera, elaborado por Sousa (2004), novas coleçôes foram obtidas em três expediçōes realizadas à região Norte, tornando possível a melhor caracterização morfológica da espécie, assim como, a verificação de ampliação de sua área de distribuição e fornecer dados para a conservação desta espécie.

\section{MATERIAL E MÉTODOS}

O estudo taxonômico foi baseado em coleçóes de herbários nacionais e internacionais: ESA, INPA, K, NY, S, SP, TEPB, US (Siglas conforme Holmgren \& Holmgren 2006).

As mensuraçōes das estruturas florais foram complementadas pelo material fresco, conservados em álcool 70\%.

A terminologia segue Radford et al. (1974), Smith \& Downs (1979), Stearn (1992) e o padrão de inflorescência, seguiu Weberling (1989). Na caracterização do tipo de vegetação foi utilizado Velozo et al. (1991).

\section{RESULTADOS E DISCUSSÃO}

Aechmea rodriguesiana (L. B. Sm.) L. B. Sm., Phytologia 19: 281. 1970. Gravisia rodriguesiana L. B. Sm., Phytologia 13(2): 153. pl. 7, fig. 18, 19. 1966. Chevaliera rodriguesiana (L. B. Sm.) L. B. Sm. \& Kress, Phytologia. 66(1): 78. 1989. TIPO: BRASIL. Amazonas: Manaus, Reserva Florestal Ducke, Bosque das Palmeiras, s.d., Rodrigues 5399 (Ноцótıpo: US!; Isótipo: INPA!). (Figura 1).

Aechmea meeana E. Pereira \& Reitz, Bradea 1: 385. 1974. Tipo: BRASIL. Amazonas: "near Manaus, Rio Maraú", Jul. 1972, Mee 66 (Holótipo: HB!).

Planta epífita ca. $70 \mathrm{~cm}$ alt. Folhas $81-121 \times 2,7-3 \mathrm{~cm}$; bainha 15-20 × 11-14 cm, elíptica; lâminas verdes a verdeamareladas, planas, espinho apical ca. $1 \mathrm{~cm}$ compr., espinhos marginais 3-8 mm compr., congestos. Escapo 57-60 cm compr., delgado, ultrapassando a bainha foliar, castanho a vináceo. Brácteas do escapo $12-30 \times 2-3 \mathrm{~cm}$, lineares, castanhas, lepidotas, espinho apical 0,8-2,5 cm, margens inteiras. Inflorescência em racemo de espigas, 6-20 espigas com 10-14 cm compr., paracládios de $1^{\mathrm{a}}$ e $2^{\mathrm{a}}$ ordem $0,5-1,8$ $\mathrm{cm}$, na base da inflorescência, eixo floral alongado e delgado, flores com maturação acrópeta. Brácteas florais envolvendo parcialmente o ovário, pouco menores que as sépalas, 3-3,8 $\times$ 1,3-1,8 cm, ovais, róseo-intenso, lepidotas, ápice cuspidado, margens inteiras. Flores 3,8-4,6 cm compr. Sépalas 1,8-2 cm compr., creme, mucronadas. Pétalas livres acima do tubo do hipanto, 2,5-2,8 × 0,3-0,4 cm, oblongas, alvas, ápice arredondado, cuculadas; apêndices petalíneos com porção livre entre a região mediana e basal da pétala, e com margens fimbriadas. Estames da série externa com filetes livres acima do tubo do hipanto 2,2-2,4 cm, os da série interna epipétalos, livres ca. $2 \mathrm{~mm}$; antera $4-5 \mathrm{~mm}$ compr., apiculada. Estilete e estigmas espiral-condupplicado, 2,5 cm compr., estigma 3, margens lobuladas, alcançando a altura da antera. Tubo do hipanto ca. $3 \mathrm{~mm}$ compr. Ovário 1,5-1,8 cm, ínfero, óvulos 
dispostos em toda a cavidade do ovário, longo-caudados. Fruto 2,8-3,5 cm, castanhos. Sementes ca. $4 \mathrm{~mm}$ compr., longo-caudadas.

Nome local - Gravatá (Sousa 393).

Distribuição e habitat - Brasil. Amazonas, entre 50-200 m.s.m. Em Floresta Ombrófila Densa Submontana (Mata de Terra Firme) e Campinas Amazônicas. São preferencialmente epífitas, vivendo muitas vezes no dorsel de árvores.

Dados fenológicos - Coletada com flores em Julho, com frutos em Novembro.

Material examinado: Brasil. Amazonas: Itacoatiara, lado direito do rio Urubu, IV.1967, Prance et al. 4789 (INPA, K, NY, US, S). Manaus, Campina do rio Cuieiras, IV.1975, Braga 89 (INPA); Distrito Agropecuário de Suframa, 02²6'S' 59048'W, VI.1992, Nee 42846 (INPA); Reserva Florestal Ducke, 02053'S 59\%88'W, XI.2000, Sousa et al. 390 (INPA, SP, TEPB); XI.2000, Sousa et al. 393 (INPA, SP); VII.2001, Sousa et al. 495 (INPA). Novo Airão, margem esquerda do rio Negro, VII.1998, Coelho 36 (ESA).

Aechmea rodriguesiana foi reconhecida como pertencente ao subgênero Chevaliera, pelas semelhanças encontradas com A. digitata L.B. Sm \& R.W. Read., espécie também deste mesmo subgênero. Uma análise mais detalhada destes dois táxons evidencia que os mesmos se assemelham apenas pela inflorescência composta, pela morfologia da bráctea floral oval com ápice cuspidado e pétalas alvas.

Aechmea rodriguesiana é bastante característica e de fácil distinção, por ser a única espécie do subgênero Chevaliera que apresenta inflorescência com várias ramificações.

Com base em novas coletas na localidade do material-tipo foi possível adicionar novas características à descrição original, além da ilustração completa de Aechmea rodriguesiana, tornando possível o fácil reconhecimento deste táxon, que é típico da floresta amazônica brasileira.

Figura 1 - Aechmea rodriguesiana L.B. Sm. A. Hábito. B. Flor protegida por bráctea floral. C. Bráctea floral em vista dorsal. D. Flor em corte longitudinal. E. Pétala com estame epipétalo, calosidades laterais e apêndices na metade inferior. F. Estigma. G. Óvulo caudado. H. Fruto. I. Fruto em corte longitudinal. J. Semente caudada (A, H-I, Sousa 390; C-G, Sousa 495). 


\section{AGRADECIMENTOS}

As autoras agradecem aos curadores dos herbários citados, pelo empréstimo e/ou apoio logístico nas visitas. A Elisete Anunciação, Tatiana Konno e Karla Arns pela companhia e ajuda nas semanas de coleta na Reserva Ducke. A pesquisadora Lourdes Soares do INPA, pela amizade e apóio logístico na minha estada em Manaus. Ao Programa CAPES/UFPI/ PICDT, pela concessão da bolsa de doutorado para a primeira autora e ao CNPq, pela bolsa de Produtividade em Pesquisa a segunda autora.

\section{BIBLIOGRAFIA CITADA}

Holmgren, P.K.; Holmgren, N.H. 2006. Online edition of Index Herbariorum. New York Botanical Garden website. (www.nybg. org/bsci/ih). Acesso: 17/06/2006.

Luther, H.E.; Sieff, E. 1994. De Rebus Bromeliacearum I. Selbyana, 15: 9-93.

Luther, H.E.; Sieff, E. 1997. De Rebus Bromeliacearum II. Selbyana, 18: $103-140$.

Luther, H.E. 2000. An Alphabetical list of bromeliad binomes. The Bromeliad Society Inc. Oregon. 98pp.

Luther, H.E. 2001. De Rebus Bromeliacearum II. Selbyana, 22: 34-67.

Luther, H.E. 2004. An Alphabetical list of bromeliad binomes. The Bromeliad Society Inc. Oregon. 109pp.

Radford, A.E, Dickison, W.C, Massey, J.R., Bell, C.R. 1974. Vascular Plant Systematics. Harper \& Row Publishers, New York. $891 \mathrm{pp}$.
Ribeiro, J. E. L. S.; Hopkins, M.J.G; Vicentini, A.; Sothers, C.A.; Costa, M.A.S., Brito, J.M.; Souza, M.A.D.; Martins, L.H.P., Lohmann, L.G.; Assunção, P.A.C.L., Pereira, E.C.; Silva, C.F.; Mesquita, M.R.; Procópio, L.C. 1999. Flora da Reserva Ducke: Guia de Identificação das plantas vasculares de uma floresta de terra-firme na Amazônia Central. Instituto Nacional de Pesquisas da Amazônia, Manaus, Amazonas. 816pp.

Smith, L.B. Downs, R.J. 1974. Pitcairnioideae (Bromeliaceae). Flora Neotropica Monograph 14 (1), Hafner Press. p.1-658.

Smith, L.B.; Downs, R.J. 1977. Tillandsioideae (Bromeliaceae). Flora Neotropica Monograph 14 (2), Hafner Press. p. 663-1492.

Smith, L.B.; Downs, R.J. 1979. Bromelioideae (Bromeliaceae). Flora Neotropica Monograph 14 (3)., Halfner Press. p. 1493-2141.

Sousa, G.M. 2004. Revisão Taxonômica de Aechmea Ruiz \& Pav. Subg. Chevaliera (Gaudich. Ex Beer) Baker, BromelioideaeBromeliaceae. Tese de Doutorado. Universidade de São Paulo, São Paulo. 181pp.

Stearn, W.T. 1992. Botanical Latim. $4^{\text {th }}$ ed. Timper . Portland. Oregon. 546pp.

Velloso, H.P.; Rangel Filho, A.L.R.; Lima, J.C.A. 1991. Classificação da vegetação brasileira adaptada a um sistema universal. IBGE/ DG/DERNA, Rio de Janeiro. 123pp.

Weberling, F. 1989. Morphology of flowers and inflorescences. University. Press. Cambridge. 405pp.

Recebido em 13/07/2006

Aceito em 29/05/2007 